Marquette University

e-Publications@Marquette

College of Education Faculty Research and

Publications

Education, College of

$2-1-2013$

Beyond Theoretical Orientations: The Emergence of a Unified Scientific Framework in Professional Psychology

Timothy P. Melchert

Marquette University, timothy.melchert@marquette.edu

Accepted version. Professional Psychology: Research and Practice, Vol. 44, No. 1 (February 2013):

11-19. DOI. (C) 2013 American Psychological Association. Used with permission. 


\title{
Beyond Theoretical Orientations: The Emergence of a Unified Scientific Framework in Professional Psychology
}

\author{
Timothy P. Melchert \\ Counselor Education and Counseling Psychology \\ Marquette University \\ Milwaukee, WI
}

\begin{abstract}
Psychology has been remarkably successful as both a basic and applied science despite serious and persistent conflict between its many theoretical camps and schools of thought. By far the most influential approaches to conceptualizing clinical practice in psychology have been the traditional theoretical orientations, even though they are widely viewed as inadequate and incomplete. This manuscript reviews the underlying reasons for these conflicts and then discusses the emergence of a unified scientific framework that moves the profession beyond these problems. Outmoded conceptual frameworks are not appropriate for a science-based profession, and professional psychology needs to consider making a systematic transition to a comprehensive scientific approach to understanding human development, functioning, and behavior change.
\end{abstract}

Keywords: unified theory, theoretical orientations, biopsychosocial, professional psychology, psychological science 
Psychology has been remarkably successful as both a basic and applied science since its founding in the late 19th century. The field has had a major influence on important areas within the social sciences, education, health care, public policy, organizations and businesses, and even on culture in general. It has helped transform society's understanding of mental health and psychological functioning, and psychosocial treatments have provided relief to countless individuals suffering from psychological dysfunction and distress. The professional practice of psychology has also grown remarkably. Psychologists played a small role in American health care before 1945 when the first licensure law for psychologists was enacted, and just 60 years later the number of licensed psychologists grew to over 85,000 (Duffy et al., 2006).

Despite its remarkable growth and many achievements, the field has also found it challenging to develop consensus explanations of personality, psychopathology, and behavior change that provide a solid scientific foundation for the clinical practice of psychology. Scientifically verified explanations have emerged regarding many psychological phenomena, but other aspects of the tremendous complexity of human psychology have been difficult to unravel and are currently understood only in outline form. This is particularly true for more complicated higher level processes that are often the focus of psychological treatment. Many basic processes of sensation, perception, cognition, affect, learning, and development are understood in detail, but explanations are much less complete for many complex processes such as the nature and development of personality and intelligence, the nature and causes of psychopathology, and the mechanisms that account for behavior change and treatment effectiveness.

Within professional psychology (PP), by far the most influential approaches to understanding personality, psychopathology, and psychotherapy have been the traditional theoretical orientations. Standard textbooks that cover this material often take a chronological approach to reviewing these orientations, starting with Freudian theory and progressing through psychodynamic, behavioral, humanistic, cognitive, systemic, multicultural, and integrative approaches. The more than 400 theoretical orientations that have now been developed vary widely in focus and scope (Corsini \& Wedding, 2008). Some

Professional Psychology: Research and Practice, Vol. 44, No. 1 (February 2013): pg. 11-19. DOI. This article is (C) American Psychological Association and permission has been granted for this version to appear in e-Publications@Marquette. American Psychological Association does not grant permission for this article to be further copied/distributed or hosted elsewhere without the express permission from American Psychological Association. 
theories focus primarily on the development of personality and psychopathology with little emphasis on the process of psychotherapy (e.g., existentialism, multicultural approaches), while others focus primarily on therapy processes and methods (e.g., interpersonal therapy, eclectic approaches). The earliest of these theories, Freudian psychoanalysis, was the most comprehensive and thorough attempt to explain all these factors, though it also ended up being the most controversial.

These theoretical orientations continue to play very important roles in PP education and practice. For example, while it is obviously not possible to learn a large number of them in detail, learning one or more of them is generally considered required training in the field. The Application for Psychology Internship, used by nearly all psychology internship programs in the Association of Psychology Postdoctoral and Internship Centers (APPIC), requires that applicants complete the following essay question: "Please describe your theoretical orientation and how this influences your approach to case conceptualization and intervention" (APPIC, 2009, p. 22). The conclusions of the American Psychological Association (APA) Assessment of Competency Benchmarks Work Group (2007) also support this approach. They noted that the "ability to formulate and conceptualize cases and plan interventions utilizing at least one consistent theoretical orientation" (p. 43) is an "essential component" for demonstrating clinical intervention skill. The Guidelines and Principles of the APA Commission on Accreditation (2009) are also consistent with this approach by noting that "The accreditation guidelines and principles are specifically intended to allow a program broad latitude in defining its philosophy or model of training and to determine its training principles, goals, objectives, desired outcomes (i.e., its "mission") and the methods to be consistent with these" (p. 4).

Given the central role that the traditional theoretical orientations have played in PP education and practice, it is remarkable how controversial they have been across the entire history of the field. The criticisms and weakness of these various orientations are very well known-standard undergraduate and graduate textbooks routinely discuss them as part of the presentation of the theories. Even the most influential current single approach, cognitive-behavioral therapy, is widely considered inadequate as an explanation for psychotherapy

Professional Psychology: Research and Practice, Vol. 44, No. 1 (February 2013): pg. 11-19. DOI. This article is (C) American Psychological Association and permission has been granted for this version to appear in e-Publications@Marquette. American Psychological Association does not grant permission for this article to be further copied/distributed or hosted elsewhere without the express permission from American Psychological Association. 
change (e.g., Kazdin, 2007). (See the sections that follow for more discussion of these issues.)

The traditional theoretical orientations in PP are perhaps universally considered to provide incomplete explanations of personality, psychopathology, and behavior change, but they continue to play central roles in the field nonetheless. Indeed, it would be difficult for many students, faculty, and practicing psychologists to imagine case conceptualizations that are not based on these orientations. The appropriateness of this practice from a scientific perspective, however, is clearly questionable. Is it appropriate for clinicians to select one or more of the traditional theoretical orientations to guide their approach to clinical practice if those orientations are widely viewed as incomplete and inadequate? Further, given that this practice is incorporated into major organizational structures within the profession, to what extent does this raise questions about the strength of the scientific foundations of the profession? This article reviews the origins and nature of these problems before going on to advocate that it is time for the field to transition to a unified science-based approach to professional practice.

To clarify the significance of these issues, this article first briefly reviews problems associated with the traditional approaches to conceptualizing professional practice in psychology and then examines the most important reasons behind the confusing conceptual foundations of the field. The article then discusses the characteristics of a comprehensive science-based solution to these problems. Relying on outmoded theoretical frameworks for education, practice, and research is not appropriate for a science-based profession, and it is critical that PP continually re-examines these issues and updates the scientific foundations on which it is based.

\section{Theoretical Conflict and Confusion in PP}

One of the more remarkable characteristics of psychology as a scientific discipline has been the proliferation of theoretical approaches to understanding the nature of psychological phenomena. Right from the start, there was major controversy regarding the most appropriate approaches to understanding psychology. Wilhelm Wundt, who established the first psychology laboratory in 1879, argued that higher

Professional Psychology: Research and Practice, Vol. 44, No. 1 (February 2013): pg. 11-19. DOI. This article is (C) American Psychological Association and permission has been granted for this version to appear in e-Publications@Marquette. American Psychological Association does not grant permission for this article to be further copied/distributed or hosted elsewhere without the express permission from American Psychological Association. 
cognitive processes should not even be investigated because they were simply too complex to understand using available experimental methods. His students were only allowed to study elemental experiences such as basic sensations, associations, and feelings. By the turn of the century, Sigmund Freud was advocating for a radically different approach to understanding human psychology that revolved around the role of the unconscious. In 1913, John Watson presented another radically different perspective, urging his colleagues to abandon their interest in consciousness and instead focus on behavior. Remarkably varied approaches to understanding human psychology continued to proliferate over the decades. Thomas Kuhn (1962) noted that such theoretical proliferation and competition also characterized the natural sciences when they were young and concluded that psychology was in a similar "immature" and preparadigmatic stage as the physical sciences were in the 17 th century.

The proliferation of theoretical approaches in PP has continued up to the present. New eclectic and integrative approaches continue to be developed (see Norcross, 2005), as well as entirely new approaches such as positive psychotherapy (Seligman, Rashid, \& Parks, 2006), attachment therapy (Wallin, 2007), personality-guided relational psychotherapy (Magnavita, 2005), and coherence therapy (Ecker \& Hulley, 2006). In addition, no individual approach has become dominant. Surveys normally find that the largest number of adherents to any one orientation, even an eclectic or integrative approach, still remains a minority, usually less than one third of the sample (Prochaska \& Norcross, 2010). The intensity of contention and conflict between the theoretical camps appears to have diminished in recent years (Goodheart \& Carter, 2008; Magnavita, 2008; Norcross, 2005), but disagreements between advocates of the differing theoretical orientations remain strong nonetheless.

In addition to conflicts between theoretical camps, there have been several other controversies and schisms that reflect confusion in the conceptual foundations of the field. In 1976, the National Council for Schools of Professional Psychology broke off from the APA because of fundamental differences regarding the appropriate training model for PP education. In 1988, a large number of psychological scientists became disillusioned with the practice emphasis of the APA and broke off to form the APA. The empirically supported treatment movement in 
PP quickly became controversial after the APA Division 12 Task Force on Promotion and Dissemination of Psychological Procedures applied the concept in 1995. Controversies surrounding recovered memories of child sexual abuse became so intense in the 1990s that they became known as the "memory wars" (Loftus \& Davis, 2006; p. 470), one of the most conflictual periods ever in the history of psychology. Concern has also grown recently regarding discredited or potentially harmful therapies. Norcross, Koocher, and Garofalo (2006) conducted a survey listing dozens of treatments and asked experts about the degree to which they believed each of them had been discredited. They found 25 treatments that were rated on average as somewhere between "probably discredited" and "certainly discredited" (e.g., sexual reorientation therapy, rebirthing therapies, Thought Field Therapy, reparenting therapy).

Controversies and conflicts between the theoretical camps and schools of thought in psychology have been so pervasive and persistent over the decades that many psychologists seem to accept them as a normal, almost natural characteristic of the field. Many leaders in psychology, however, have been concerned that the field has become so conflictual and fractured that it might not be able to continue as a scholarly discipline (e.g., Gardner, 2005; Kendler, 2002; Rychlak, 2005; Staats, 2005; Sternberg, 2005). Driver-Linn (2003) noted that "Perceptions of psychology as beleaguered by fractionation and uncertainty are almost ubiquitous" (p. 270).

\section{Reasons Underlying the Theoretical and Conceptual Confusion in PP}

There is a great deal of consensus regarding the underlying reasons for the conflicts and contention within PP. These reasons are important for identifying solutions to the conflicts and so they are briefly reviewed next. There are four issues in particular that are important for understanding why theoretical development in the discipline has been especially complicated. 


\section{Philosophical Underpinnings of Many Theoretical Orientations}

The theoretical and philosophical underpinnings of the historically important theoretical orientations in PP are generally wellknown. While the details involved are highly complicated, the basic issues can be easily summarized. Many of these orientations are based on foundational assumptions or first principles that take widely varying perspectives on human nature (e.g., biologically based drives in Freudian theory, the blank slate of nearly complete malleability in behaviorism, an optimistic self-actualizing tendency in humanistic theories, a postmodern constructivism in solution-focused therapy). These philosophical starting points often conflict in fundamental ways that lead to irreconcilable differences in the understanding of human psychology and behavior change (Messer \& Winokur, 1980; Wood \& Joseph, 2007). Adherence to these orientations consequently often involves acceptance of their underlying philosophical assumptions or worldview as opposed to being convinced by the weight of the scientific evidence examining their validity. As a result, disagreements between adherents of the different theories sometimes resemble philosophical or political disputes more than scientific ones.

\section{Nonfalsifiability of Psychological Theories}

From a scientific standpoint, many of the traditional theoretical orientations in psychology suffer from a second critical weakness. The purported mechanisms involved in the development of personality and psychopathology or in behavior change obviously differ greatly across the theories (e.g., developmental fixations, one's learning history, imposed conditions of worth, depressogenic cognitions, a constructed phenomenological worldview). Nonetheless, many of these theories have been used to explain virtually all outcomes that occur in individual cases, and it is consequently difficult to disprove that a particular theory could account for any particular outcome (Popper, 1963). Instead of evaluating these issues on the basis of logical scientific analysis, students learning the profession are often advised to choose a theoretical orientation based on the fit between the orientations and their personality and worldview (e.g., Corsini \& Wedding, 2008; Truscott, 2010).

Professional Psychology: Research and Practice, Vol. 44, No. 1 (February 2013): pg. 11-19. DOI. This article is (C) American Psychological Association and permission has been granted for this version to appear in e-Publications@Marquette. American Psychological Association does not grant permission for this article to be further copied/distributed or hosted elsewhere without the express permission from American Psychological Association. 
The individual credited with first explaining the nature of this problem is the philosopher Karl Popper (1902 - 1994). As a young student in Vienna in 1919, he heard both Freud and Einstein present their work and was very impressed with both their theories. He also noticed a fundamental difference between them, however (Popper, 1963). Freud presented his theory in terms that made it amenable to confirmation, while Einstein's theory had testable implications which, if false, would prove the theory wrong. Popper noted that many theories such as Freudianism, Adlerianism, or Marxism were only amenable to confirmation and could not be refuted. He therefore judged them to be poor theories. Popper argued that scientific theories must be refutable and, further, that genuine tests of theories are attempts to refute them.

\section{Complexity of Human Psychology}

The complicated evolution of theory in psychology also cannot be understood without appreciating the tremendous complexity of the subject matter involved. The extraordinary intricacy, complexity, and range of psychological phenomena make psychology an endlessly fascinating field of study, but also highly challenging. The human brain is almost unfathomably complex. In just a three-pound organ, roughly 100 billion neurons each with an average of 1,000 synaptic connections carry our own personal history, our family's history, and even the evolutionary history of our species, while also constantly interacting with, being shaped by, and even creating one's environment, at co-occurring subconscious and conscious levels. Indeed, the human mind appears to be the most complex phenomenon humans have ever attempted to understand. The biologist Richard Dawkins noted that "... we animals are the most complicated and perfectly designed pieces of machinery in the known universe" (1976, p. xxii), while E. O. Wilson stated that "...the most complex systems known to exist in the universe are biological, and by far the most complex of all biological phenomena is the human mind" (1998, p. 81).

Some of the main critiques of the traditional theoretical orientations have focused on their failure to fully incorporate biological and sociocultural influences on development and functioning. From a

Professional Psychology: Research and Practice, Vol. 44, No. 1 (February 2013): pg. 11-19. DOI. This article is (C) American Psychological Association and permission has been granted for this version to appear in e-Publications@Marquette. American Psychological Association does not grant permission for this article to be further copied/distributed or hosted elsewhere without the express permission from American Psychological Association. 
scientific perspective, there is no question that all levels of natural organization are important to understanding human psychology. No explanation of human development and functioning is complete that does not emphasize the interactions between biological (e.g., genetics, neurophysiology, physical health, and disease), psychological (e.g., cognition, emotion, behavior), and sociocultural influences on human psychology (e.g., family, community, culture, religion, education, socioeconomic factors). The traditional theoretical orientations in psychology, however, were generally not designed to be comprehensive in this manner.

\section{Power and Precision of Available Scientific Tools}

Another critical perspective for understanding the evolution of scientific disciplines involves the power and precision of the scientific tools available for examining phenomena. The role these tools play in the development of the physical sciences is very well-known, but their importance is often underappreciated in the social sciences. Scientific progress is directly dependent on these tools, and some of the most important ones have been conceptual rather than technological. For example, mathematics in Europe was written out in words prior to the 13 th century when algebra and symbolic mathematics were invented. Vastly more complex calculations could then be performed and science and commerce were transformed as a result. Four centuries later, Newton's and Leibnitz's invention of calculus proved to be so useful that science was again transformed. The use of calculus quickly led to major advances in understanding the nature of gravity, heat, light, sound, fluid dynamics, electricity, and magnetism. The more recent development of statistics and advanced mathematical modeling again transformed the kinds of phenomena that could be investigated and explained.

Scientific progress is also heavily dependent on the development of technological tools. For example, Copernicus hypothesized that the earth revolved around the sun in 1543, but his hypothesis could not be confirmed until Galileo built his first telescope in 1609. Each further advance in telescope technology over the centuries has tended to result in important advances in understanding the cosmos. The microscope has been one of the most versatile and transformative 
scientific instruments ever invented. Van Leeuwenhoek (1632-1723) made the best early instruments, capable of 270x magnification, and became the first person to observe protozoa, bacteria, spermatozoa, blood corpuscles, and blood circulation through capillaries. Biology was transformed as a result. The next revolutionary advance in microscopes in the 1930s using beams of electrons instead of beams of light allowed very small objects such as viruses, chromosomes, and nucleic acids (including deoxyribonucleic acid) to be observed, and biology was transformed once again.

Many recent advances in science would obviously be impossible without the electronic computer. Advances in brain imaging, genetics, and particle physics, for example, require massive amounts of data processing in addition to highly sophisticated technological equipment. Recent "big science" projects such as the Human Genome Project and the Large Hadron Collider will actually generate more scientific data by several orders of magnitude than what has been collected in all of prior human history (Hey \& Trefethen, 2003). Such capabilities are even transforming the way science is conducted in these areas. Instead of the traditional approach, which can be summarized as "Hypothesize, design and run experiment, analyze result," the new approach involves "Hypothesize, look up answer in database" (Lesk, 2004, p. 1).

Recent improvements involving instrumentation, measurement, infomatics, and mathematical modeling are having a revolutionary impact on the neurosciences in particular. For example, the very high spatial and temporal resolution in magnetoencephalography (MEG) brain scanning is making it possible to make highly precise measurements of neuronal activity-(the difference between MEG and functional magnetic resonance imaging is analogous to watching brain activity with a high resolution video camera compared with a series of poorly focused still photos). Instead of investigating psychological phenomena from the perspective of "bottom-up" connections from one neuron to the next, or "top-down" models such as the organization of intelligence through the factor analysis of IQ test data, for the first time it is becoming possible to investigate comprehensive, detailed, multilevel models that simultaneously combine both bottom-up and top-down approaches in one model (Wood et al., 2006).

Professional Psychology: Research and Practice, Vol. 44, No. 1 (February 2013): pg. 11-19. DOI. This article is (C) American Psychological Association and permission has been granted for this version to appear in e-Publications@Marquette. American Psychological Association does not grant permission for this article to be further copied/distributed or hosted elsewhere without the express permission from American Psychological Association. 
Given the complexity of psychological phenomena and the limited scientific tools that have been available to study them, it is completely understandable that science is only now beginning to unravel the nature of more complex psychological processes. In hindsight, it was perhaps inevitable that many different explanations would be offered to explain the tremendous biopsychosocial complexity of human psychology, just as there were many diverse explanations offered to explain gravity, electricity, magnetism, heat, light, and sound when the physical sciences were young (Kuhn, 1962). Because of the lack of a single scientific paradigm for understanding psychological phenomena, Kuhn concluded that psychology was an "immature," preparadigmatic science. Characterizing psychology in this way emphasizes the underdeveloped state of theory in the field but fails to emphasize the reasons for that underdevelopment. PP may still be in its preparadigmatic stage of development, but the reasons primarily involve the complexity of the subject matter and the limited scientific tools that have been available. Less complex phenomena will naturally be described and explained before more complex phenomena. If the human mind and brain truly are the most complex systems in our universe, it is only natural that they are understood in less detail than other less complicated classes of natural phenomena.

Due to the above reasons, the traditional theoretical orientations have not been able to adequately explain the complexity of human psychology. Psychological science has been advancing steadily, however. The question now facing the field is whether the science of psychology has advanced sufficiently that a solution to this problem is now available.

\section{Is a Single Unified Theory the Solution for Psychology?}

The discovery of a single, unified theory that successfully explained human development, functioning, and behavior change would obviously bring PP out of its preparadigmatic stage of development. There have been many calls over recent decades for a unified theory that would solve the preparadigmatic theoretical confusion in psychology (e.g., Anchin, 2008; Magnavita, 2006; Sternberg, 2005). There are clear reasons, however, why such a

Professional Psychology: Research and Practice, Vol. 44, No. 1 (February 2013): pg. 11-19. DOI. This article is (C) American Psychological Association and permission has been granted for this version to appear in e-Publications@Marquette. American Psychological Association does not grant permission for this article to be further copied/distributed or hosted elsewhere without the express permission from American Psychological Association. 
theory is unlikely to emerge in the near future. The experience of the other sciences suggests why.

Physics is the oldest of the sciences (more than 2 millennia old) and has certainly been successful in explaining a wide range of natural phenomena from the exceedingly small (e.g., subatomic particles) to the very large (e.g., the cosmos). Despite all its achievements, however, physics has not yet discovered a unified theory that explains matter and energy. In fact, there are critically important aspects of the physical world about which very little is known, from the level of particle physics to the cosmos (e.g., $95 \%$ of the universe consists of "dark matter" and "dark energy" about which very little are known; Randall, 2011). The discovery of a unified theory of matter and energy is regarded by many as the ultimate goal of physics, but the field may still be a long way from reaching that goal (Mitchell, 2009).

Biology is a much younger science than physics but has also been highly successful. Biology was largely a descriptive science until Darwin's 1859 On the Origin of Species, and it took until the 1930s and 1940 s before the full significance of natural selection was appreciated (Quammen, 2006). Modern evolutionary theory is continuing to develop (Larson, 2004), and there is obviously a great deal about many biological processes that still remains to be discovered. There is some excitement that the West, Brown, and Enquist metabolic scaling theory may bring biology together under one unified theoretical framework, but that possibility is still far from being proven (Mitchell, 2009).

Despite being very well-established and successful disciplines, physics and biology have not yet discovered unified theories for explaining phenomena within those fields. In contrast, psychology is a much younger discipline that investigates extraordinarily complex phenomena. The power and precision of scientific tools have been advancing, but clearly much remains to be done to unravel the complexity of human psychology. There is no reason to expect that a unified theory will be discovered in psychology before one is discovered in physics or biology.

It is critical to recognize, however, that a unified scientific theory of psychology is not necessary for psychology to leave behind

Professional Psychology: Research and Practice, Vol. 44, No. 1 (February 2013): pg. 11-19. DOI. This article is (C) American Psychological Association and permission has been granted for this version to appear in e-Publications@Marquette. American Psychological Association does not grant permission for this article to be further copied/distributed or hosted elsewhere without the express permission from American Psychological Association. 
its preparadigmatic past. There are now no unified theories in physics, chemistry, or biology, but those fields are all viewed as solidly scientific. It is also not necessary to explain all phenomena within a particular area for a field to be considered scientific. Take the case of medicine. Certainly the success of the biomedical sciences is impressive. Nonetheless, the amount that remains to be discovered is substantial. For example, there remain a large number of idiopathic diseases for which the causes and cures are unknown (e.g., Alzheimer's and Parkinson's disease, most seizures, multiple sclerosis, rheumatoid arthritis, Type I diabetes). Concern is also growing about the safety of many medical procedures and the widespread use of tests and interventions that may cause more harm than benefit (e.g., Institute of Medicine, 2000; U.S. Preventive Services Task Force, 2012).

The point at which medicine in the U.S. reached the "tipping point" when it most clearly transitioned from primarily an art to a science was in 1910 when Abraham Flexner submitted his report on the state of medical education. Biology had been making many important advances and the practice of medicine was transforming dramatically at the end of the 19th century. In 1878, Pasteur introduced the germ theory of infection and in the following year tested the first vaccination. Sterilization of medical instruments had been introduced and was becoming widespread toward the end of the century-(before antiseptic methods were introduced, death rates following amputations, for example, reached $100 \%$ for some physicians; Porter, 1997). To evaluate whether American medical education was sufficiently science-based, Flexner visited and rated nearly every one of the 168 medical schools in the U.S. and Canada. His highly influential report included his ratings and often scathing criticisms of the individual schools, and several of them closed soon after as a result. Over the next decades, $42 \%$ of the schools closed, and the schools that remained had significantly increased their admission standards and laboratory and clinical training requirements (Hiatt \& Stockton, 2003).

Enough was discovered in physics, chemistry, and biology that those fields long ago reached the tipping point when they became considered scientific (and paradigmatic in the Kuhnian sense). Unified theories for explaining phenomena within those disciplines clearly had 
not been discovered, but enough verified explanations of important phenomena had accumulated, and these in turn enabled the applied fields of engineering and medicine to be practiced in an increasingly safe and effective manner.

Psychology has been on a developmental course similar to that of the natural sciences. Psychological science has been advancing steadily, and PP is increasingly embracing the need to base clinical intervention on reliable research evidence. Indeed, APA officially endorsed the evidence-based approach to clinical practice in 2005 (APA, 2005). Nonetheless, confusion persists regarding the appropriate theoretical and scientific foundations for practicing psychology. The question now facing PP is whether the field has reached the tipping point where its practitioners can converge around a unified sciencebased approach to PP education, practice, and research.

\section{The Solution: A Metatheoretical Framework}

The answer to this question depends on whether psychological science has progressed sufficiently to be able to provide a unified scientific approach to clinical practice that can replace the diverse assortment of irreconcilable theoretical orientations that have historically guided case conceptualization and intervention in the field. If PP is ready to make this transition, it would, of course, represent a major milestone for the field. But what would the new approach look like?

As was just noted, it is not currently possible for a true unified theory of psychology to provide the foundation for unifying PP around a single scientific approach-such a theory is unlikely to be discovered for a very long time (if ever). Instead, the solution to this problem is (naturally) the same as it was for the natural sciences. When it comes to discrete, less complex phenomena, scientific laws and theories are often able to explain the processes involved. Explanations of highly complex phenomena involving many variables and processes are frequently not yet available, however. As a result, metatheoretical frameworks and models are needed to integrate what is known and provide approximate explanations of these phenomena (Mitchell, 2009; Rodgers, 2010). Metatheoretical frameworks attempt to identify the most essential characteristics that need to be integrated to

Professional Psychology: Research and Practice, Vol. 44, No. 1 (February 2013): pg. 11-19. DOI. This article is (C) American Psychological Association and permission has been granted for this version to appear in e-Publications@Marquette. American Psychological Association does not grant permission for this article to be further copied/distributed or hosted elsewhere without the express permission from American Psychological Association. 
understand complex phenomena, and specific models built from these metatheories can then be empirically tested and refined. Whether it be the climate, the behavior of galaxies or subatomic particles, or the development of personality disorders, the refinement of these models results in increasingly more complete and accurate explanations of phenomena.

At the metatheoretical level, the outlines of the framework needed to understand human psychology are clear. At the most general level, there is no disagreement across the sciences and humanities that human psychology is determined by a range of psychological, sociocultural, and biological factors that interact through complex developmental processes. The influence of specific factors varies dramatically depending on the phenomenon and the developmental, environmental, and other contextual factors involved, and of course more is known about some phenomena than others. But taken together, the amount that is known is extensive. Psychologists are probably in agreement that all the major "waves" of theory development in the field (e.g., psychodynamic, behavioral, humanistic, cognitive, systemic, multicultural) have contributed important insights into understanding human psychology, but that these insights also need to be integrated with those from the neuro- and biological sciences, the various social sciences, and the humanities to gain a comprehensive understanding. Of course, the integration of all these perspectives is staggeringly complex and will require a huge amount of additional research. At the general metatheoretical level, however, there is unanimity that human psychology cannot be understood without taking a comprehensive, integrative approach that spans the biological, psychological, and sociocultural levels of natural organization.

Again, the question is not whether all of human psychology can now be explained with precision and detail, but whether enough is known to justify a transition away from the clearly incomplete and inadequate theories of the past to a single, unified, science-based metatheoretical orientation. Psychological phenomena are obviously tremendously complex and the amount that remains to be discovered is huge, to be sure. Nonetheless, a great deal is now known. Is it enough to justify a general transition away from practicing psychology primarily as an art where one selects from among a diverse array of 
theoretical orientations, and instead move to a unified science-based approach that essentially includes just one metatheoretical orientation?

The evidence for a unified science-based metatheoretical framework for psychology is overwhelming. At its most general level, this framework would be based on a biopsychosocial perspective. This perspective was described by George Engel in 1977, though other terms or frameworks could be used to reflect this perspective (e.g., Bronfenbrenner's, 2001bioecological approach). Whatever term or framework is used, it needs to encompass the biological and sociocultural levels of natural organization that are just below and above that of human psychology. Human development and functioning simply cannot be explained without capturing the interaction of all three of these general levels of natural organization. The term biopsychosocial is widely known and accepted throughout health care and human service fields (e.g., see APA, 2006), and the biopsychosocial framework has been incorporated into medical education throughout the U.S. and Europe (Frankel, Quill, \& McDaniel, 2003). It has also been adopted within several of the clinical specializations in PP (e.g., in child, school, health, and addiction psychology, neuropsychology, and geropsychology; see Martin, Weinberg \& Bealer, 2007; Seagull, 2000; Shah \& Reichman, 2006; Suls \& Rothman, 2004; Williams \& Evans, 2003). Therefore, it is a strong candidate for the basic scientific framework needed in the field.

The practice of psychology has revolved around the traditional theoretical orientations throughout its history, however, and replacing those as the predominant frameworks for conceptualizing clinical practice would involve a major readjustment for many psychologists. For generations, students and psychologists have had to answer questions about their chosen theoretical orientations, and many clinicians would consider it completely foreign to conceptualize cases in a manner that did not revolve around those orientations. If the field were to abandon these practices and transition to a unified biopsychosocial metatheoretical orientation, what would that orientation look like and what would replace the traditional practices?

Professional Psychology: Research and Practice, Vol. 44, No. 1 (February 2013): pg. 11-19. DOI. This article is (C) American Psychological Association and permission has been granted for this version to appear in e-Publications@Marquette. American Psychological Association does not grant permission for this article to be further copied/distributed or hosted elsewhere without the express permission from American Psychological Association. 


\section{Implications of a Unified Biopsychosocial Approach to PP}

The impact of a unified science-based approach on PP education, practice, and research would be much greater in some areas than in others. For example, the standard psychosocial history and multiaxial Diagnostic and Statistical Manual diagnosis already require that information regarding all three biopsychosocial domains be collected, evaluated, and integrated. Other practices would change markedly, however. Several of these issues have been discussed extensively in the specializations that already rely heavily on the biopsychosocial approach (e.g., child, school, health, and addiction psychology, neuropsychology, and geropsychology). They have been discussed far less with regard to the general practice areas, however, or for PP as a whole (for recent exceptions, see Henriques, 2011 and Melchert, 2011). Below are several issues that would need to be discussed as part of a systematic transition to a unified science-based biopsychosocial approach for PP as a whole.

\section{Only One Theoretical Orientation for Conceptualizing Clinical} Practice in Psychology Would Be Taught. Many PP education programs currently take a survey approach to teaching the traditional theoretical orientations while other programs emphasize the theoretical orientations of their faculty. Taking a science-based biopsychosocial approach to understanding psychology results in a very different curriculum, however. From this perspective, neither individual clients nor demographic and diagnostic groups can be understood without taking a comprehensive, integrative biopsychosocial approach. Therefore, students would no longer learn to conceptualize cases according to a chosen theoretical orientation, but would instead learn to conceptualize cases according to a biopsychosocial approach. Particular ramifications of this perspective are discussed below.

\section{PP Would Become More Clearly Oriented Around Being a} Health Care Profession. PP has frequently been conceptualized as primarily a service industry where clients interested in obtaining psychological services can choose a clinician whose services and orientation are consistent with the individual's preferences and needs (Melchert, 2011). In contrast, governments license psychologists as

Professional Psychology: Research and Practice, Vol. 44, No. 1 (February 2013): pg. 11-19. DOI. This article is (C) American Psychological Association and permission has been granted for this version to appear in e-Publications@Marquette. American Psychological Association does not grant permission for this article to be further copied/distributed or hosted elsewhere without the express permission from American Psychological Association. 
health care providers responsible for meeting the behavioral health needs of the public and insurers reimburse psychologists for the health care services they provide. Defining PP as a health care profession emphasizes its role as an applied science that is based on science and professional ethics. From this perspective, psychologists address patients' behavioral health needs and work to improve their biopsychosocial functioning using interventions that have been evaluated for safety and effectiveness.

\section{A Comprehensive, Holistic Perspective on Behavioral Health} Care Emphasizes Functioning Broadly Across the Important Domains Of Life. Given the interactions across the psychological, sociocultural, and biological domains, a comprehensive, holistic view of human psychology emphasizes individuals' functioning across all the biopsychosocial domains. Many of the traditional theoretical orientations focused on particular psychological factors (e.g., cognitive therapy for depression, behavioral therapy for fear and anxiety, clientcentered therapy for low self-worth). Taking a holistic biopsychosocial perspective certainly maintains an emphasis on psychological factors, but also broadens the focus of assessment and treatment to physical health as well as functioning within the family, school and work settings, and community.

A useful starting point for gaining a comprehensive understanding of the behavioral health needs and biopsychosocial functioning of the public is an epidemiological perspective. To illustrate the implications of this perspective, the prevalence data reported in the Diagnostic and Statistical Manual (American Psychiatric Association, 2000) finds that the most common problems experienced by the general public involve sexuality (i.e., hypoactive sexual desire and orgasmic disorder in females, premature ejaculation in males) and nicotine and alcohol dependence (all of which are more prevalent than major depression, the next most common disorder; Melchert, 2011). In addition, nearly $50 \%$ of the U.S. population lives with a chronic health condition that requires routine treatment and/or activity limitations (Partnership for Solutions, 2004). The data regarding relationship problems, parenting, educational attainment, vocational effectiveness, financial stress, and other factors also indicate that large numbers of individuals are dealing with significant challenges and are not functioning optimally in several areas. Despite their clear 
importance to behavioral health, many of these topics receive limited attention in current PP education. A biopsychosocial perspective, on the other hand, emphasizes all these issues.

\section{Teaching the Biological and Sociocultural Bases of Behavior} Would Be Strengthened. A biopsychosocial approach to PP education would continue to emphasize the psychological bases of behavior but would also include more systematic coverage of the biological and sociocultural bases of behavior. In addition to the psychological domain, a comprehensive understanding of human psychology requires training in evolutionary psychology, the neurosciences, physical health and disease, the influence of childhood, families, relationships, neighborhoods, culture, religion, educational achievement, and vocational stability. Though this type of training would be significantly more extensive than what is currently offered in most PP education programs, students typically learn a significant amount regarding these topics because of their importance in clients' lives. Their learning about these topics is often quite haphazard, however, because PP education currently tends not to cover them systematically. It is important to note that the same issue applies to physical health and medicine, a comprehensive understanding of which spans all the way from molecular biology to public health and sociocultural levels. Approaches that do not take all these levels into account are limited in both explanatory power and effectiveness.

\section{The Traditional Theoretical Orientations Would Generally Be} Reconceptualized as Therapies. When taking a science-based biopsychosocial approach to understanding human psychology, the term theory and related terms would normally be used in their scientific sense to refer to explanations of phenomena that have survived experimental tests aimed at verification and falsification. As a result, the traditional theoretical orientations would generally no longer be referred to as theoretical orientations because of their inadequacies as scientific theories (e.g., their reliance on assumptions or worldviews, their inability to be falsified; see above). However, many of the treatments based on these orientations provide demonstrably effective therapies for addressing behavioral health needs. Therefore, while a single unified biopsychosocial approach would be used to understand human development and functioning, there is a full range of evidence-based psychologically, socioculturally, and biologically

Professional Psychology: Research and Practice, Vol. 44, No. 1 (February 2013): pg. 11-19. DOI. This article is (C) American Psychological Association and permission has been granted for this version to appear in e-Publications@Marquette. American Psychological Association does not grant permission for this article to be further copied/distributed or hosted elsewhere without the express permission from American Psychological Association. 
oriented therapies and other interventions (e.g., support groups, physical exercise, and diet) that psychologists can safely and effectively use to address individuals' problems and improve their biopsychosocial functioning.

\section{Many Long-Standing Conflicts Within the Field Would Quickly} Become Irrelevant. The historical practice of selecting a theoretical orientation to guide one's clinical practice naturally led to competition between the theoretical camps. A unified biopsychosocial approach, on the other hand, involves a fundamentally different framework that renders much of this competition obsolete. The biopsychosocial approach integrates the best scientific evidence available regarding all the important influences on a person in order to explain the development and functioning of the whole person, at the macro level, rather than focus on particular midlevel psychological processes as have many of the traditional theoretical orientations. This approach is tremendously complex, to be sure. But this complexity is unavoidable because human nature is simply very complicated.

The biopsychosocial approach relies on the accumulation of scientific knowledge regarding all of the many different influences on human development and functioning. From this perspective, all levels of natural organization are important, all perspectives that help explain psychological processes are valued, as are all therapies and other interventions that are demonstrated to improve biopsychosocial functioning. Traditional conflicts about the superiority of particular theoretical orientations, the relevance of research to practice, the superiority of qualitative versus quantitative research, or untested claims regarding the etiology of psychopathology or the mechanisms that account for therapeutic change all quickly fade in importance when a comprehensive science-based approach is applied.

\section{Psychology Would Be Better Able to Integrate Into the Health} Care Professions. Integrating behavioral health care into primary health care has recently become a priority for many psychologists (APA Presidential Task Force on the Future of Psychology Practice, 2009; Goodheart, 2010). This is occurring at the same time that medicine is increasingly recognizing the importance of behavior and lifestyle to physical health and disease (e.g., Institute of Medicine, 2004). Improving the overall health of the general public will require

Professional Psychology: Research and Practice, Vol. 44, No. 1 (February 2013): pg. 11-19. DOI. This article is (C) American Psychological Association and permission has been granted for this version to appear in e-Publications@Marquette. American Psychological Association does not grant permission for this article to be further copied/distributed or hosted elsewhere without the express permission from American Psychological Association. 
that mental health, behavior, and lifestyle issues are more effectively addressed in health care generally, and this may in turn require that psychologists become better integrated into primary health care.

Taking a biopsychosocial approach to PP education and practice will not only facilitate such integration, it may even be necessary before psychologists can easily integrate into primary health care. Traditional approaches to PP that revolve around theoretical orientations are often not easily understood by medical health care professionals and the other stakeholders in health care systems. The biopsychosocial approach, on the other hand, is quite familiar to other health care and human service professionals. Sharing a general conceptual framework is important to the successful integration of PP into primary health care.

\section{Conclusion}

The science of psychology has advanced significantly in recent years. Despite the very large amount that remains to be discovered, the available evidence overwhelmingly points to a comprehensive, integrative biopsychosocial approach for understanding human psychology. PP as a whole has not yet systematically adopted this perspective and instead continues to rely on many past practices associated with adopting one or more of the traditional theoretical orientations. The time has come to evaluate whether PP should discontinue those practices and replace them with a unified sciencebased biopsychosocial approach to education, practice, and research in the field. Given the inexorable progress of science, this is likely a question of when this transition will occur rather than if it occurs.

Adopting a unified science-based approach to understanding human psychology will allow PP to leave behind its preparadigmatic past, a period marked by large amounts of conflict, contention, and controversy. Many of those conflicts and controversies are outdated at this point because the biopsychosocial complexity of human psychology is simply far greater than what the traditional theoretical orientations (even when combined) are able to capture. Those conflicts and controversies have caused a great deal of distraction and inefficiency, and leaving them behind will provide significant relief for the field as well as allow time and energy to be focused more 
productively on improving our understanding of human psychology and improving behavioral health care effectiveness. There is not enough space here to illustrate how more detailed explanations of the links between biopsychosocial processes are leading to a more complete understanding of human development, functioning, and behavior change, but interested readers are referred to several fascinating programs of research that are making major contributions to informing human psychology and behavioral health care (e.g., Davidson \& Begley, 2012; Kahneman, 2011; Porges, 2011; Sroufe, Egeland, Carlson, \& Collins, 2005).

Psychologists' expertise spans all the biopsychosocial domains of functioning. We are naturally situated at the intersection of these three levels of natural organization and are very knowledgeable regarding the interplay of mental and physical health, of family and sociocultural influences on physical and mental health, and the myriad other interactions between the biopsychosocial domains. As a result, the profession is in a natural position for leading efforts to improve health and well-being in general. Entering the paradigmatic era in PP will not only facilitate this type of leadership, it may very well be necessary for moving ahead effectively in this direction. If the profession is successful in this regard, PP is on the verge of entering a truly exciting period in its development.

\section{References}

American Psychiatric Association. (2000). Diagnostic and statistical manual for mental and emotional disorders (4th ed., text revision). Washington, DC: Author.

American Psychological Association. (2005). Policy statement on evidencebased practice in psychology. Retrieved from http://0www.apa.org.libus.csd.mu.edu/practice/resources/evidence/evidencebased-statement.pdf

American Psychological Association. (2006). Health care for the whole person statement of vision and principles. Retrieved from [www.apa.org/practice/hcwp_statement.html]

American Psychological Association Assessment of Competency Benchmarks Work Group. (2007). A developmental model for the defining and

Professional Psychology: Research and Practice, Vol. 44, No. 1 (February 2013): pg. 11-19. DOI. This article is (C) American Psychological Association and permission has been granted for this version to appear in e-Publications@Marquette. American Psychological Association does not grant permission for this article to be further copied/distributed or hosted elsewhere without the express permission from American Psychological Association. 
NOT THE PUBLISHED VERSION; this is the author's final, peer-reviewed manuscript. The published version may be accessed by following the link in the citation at the bottom of the page.

measuring competence in professional psychology. Washington, DC: Author.

American Psychological Association Commission on Accreditation. (2009). Guidelines and principles for accreditation of programs in professional psychology. Washington, DC: American Psychological Association.

American Psychological Association Presidential Task Force on the Future of Psychology Practice. (2009). Final report. Retrieved from http://0www.apa.org.libus.csd.mu.edu/pubs/info/reports/future-practice.aspx

Anchin, J. (2008). Pursuing a unifying paradigm for psychotherapy: Tasks, dialectical considerations, and biopsychosocial systems metatheory. Journal of Psychotherapy Integration, 18, 310-349. doi: $10.1037 / \mathrm{a} 0013557$

Association of Psychology Postdoctoral and Internship Centers. (2009). Application for psychology internships. Retrieved from [http://www.appic.org/match/5_3_match.html]

Bronfenbrenner, U. (2001). The bioecological theory of human development. In N. J.Smelser \& P. B.Baltes (Eds.), International encyclopedia of the social and behavioral sciences (Vol. 10, pp. 6963-6970). New York, NY: Elsevier. doi:10.1016/B0-08-043076-7/00359-4

Corsini, R. J., \& Wedding, D. (2008). Current psychotherapies (8th ed.). Belmont, CA: Thomson Brooks/Cole.

Davidson, R. J., \& Begley, S. (2012). The emotional life of your brain: How its unique patterns affect the way you think, feel, and live, and how you can change them. New York, NY: Hudson Street Press.

Dawkins, R. (1976). The selfish gene. New York, NY: Oxford University Press.

Driver-Linn, E. (2003). Where is psychology going? Structural fault lines revealed by psychologists' use of Kuhn. American Psychologist, 58, 269-278. doi:10.1037/0003-066X.58.4.269

Duffy, F. F., Wilk, J., West. J. C., Narrow, W. E., Rae. D. S., Hall, R., ...Manderscheid, R. W. (2006). Mental health practitioners and trainees. In R. W.Manderscheid \& J. T.Berry (Eds.), Mental health: United States, 2004 (pp. 256-309). Rockville, MD: U.S. Department of Health and Human Services, Substance Abuse and Mental Health

Professional Psychology: Research and Practice, Vol. 44, No. 1 (February 2013): pg. 11-19. DOI. This article is (C) American Psychological Association and permission has been granted for this version to appear in e-Publications@Marquette. American Psychological Association does not grant permission for this article to be further copied/distributed or hosted elsewhere without the express permission from American Psychological Association. 
NOT THE PUBLISHED VERSION; this is the author's final, peer-reviewed manuscript. The published version may be accessed by following the link in the citation at the bottom of the page.

Services Administration. Retrieved from [http://store.samhsa.gov/shin/content/SMA06-4195/SMA064195.pdf]

Ecker, B., \& Hulley, L. (2006). Coherence therapy practice manual and training guide. Oakland, CA: Pacific Seminars.

Engel, G. L. (1977). The need for a new medical mode: A challenge for biomedicine. Science, 196, 129-136. doi:10.1126/science. 847460

Frankel, R. M., Quill, T. E., \& McDaniel, S. H. (Eds.). (2003). The biopsychosocial approach: Past, present, and future. Rochester, NY: University of Rochester Press.

Gardner, H. (2005). Scientific psychology: Should we bury it or praise it. In R. J.Sternberg (Ed.), Unity in psychology: Possibility or pipedream? (pp. 77-90). Washington, DC: American Psychological Association. doi: $10.1037 / 10847-005$

Goodheart, C. D. (2010). Economics and psychology practice: What we need to know and why. Professional Psychology: Research and Practice, 41, 189-195. doi:10.1037/a0019498

Goodheart, C. D., \& Carter, J. A. (2008). The proper focus of evidence-based practice in psychology: Integration of possibility and probability. In W. B.Walsh (Ed.), Biennial review of counseling psychology (Vol. 1, pp. 47-70). New York, NY: Taylor \& Francis Group. doi:10.1037/a0019498

Henriques, G. R. (2011). A new unified theory of psychology. New York, NY: Springer. doi: 10.1007/978-1-4614-0058-5

Hey, T., \& Trefethen, A. (2003). The data deluge: An e-science perspective. In F.Berman, A.Hey, \& G.Fox (Eds.), Grid computing-Making the global infrastructure a reality (pp. 809-824). New York, NY: John Wiley \& Sons.

Hiatt, M. D., \& Stockton, C. G. (2003). The impact of the Flexner Report on the fate of medical schools in North America after 1909. Journal of American Physicians Surgeons, 8, 37-40.

Institute of Medicine. (2000). To err is human: Building a safer health system. Washington, DC: National Academy Press.

Professional Psychology: Research and Practice, Vol. 44, No. 1 (February 2013): pg. 11-19. DOI. This article is (C) American Psychological Association and permission has been granted for this version to appear in e-Publications@Marquette. American Psychological Association does not grant permission for this article to be further copied/distributed or hosted elsewhere without the express permission from American Psychological Association. 
NOT THE PUBLISHED VERSION; this is the author's final, peer-reviewed manuscript. The published version may be accessed by following the link in the citation at the bottom of the page.

Institute of Medicine. (2004). Improving medical education: Enhancing the behavioral and social science content of medical school curricula. Washington, DC: Author.

Kahneman, D. (2011). Thinking, fast and slow. New York, NY: Farrar, Straus, \& Giroux.

Kazdin, A. E. (2007). Mediators and mechanisms of change in psychotherapy research. Annual Review of Clinical Psychology, 3, 1-27. doi:10.1146/annurev.clinpsy.3.022806.091432

Kendler, H. H. (2002). A personal encounter with psychology (1937-2002). History of Psychology, 5, 52-84. doi:10.1037/1093-4510.5.1.52

Kuhn, T. S. (1962). The structure of scientific revolutions. Chicago, IL: University of Chicago Press.

Larson, E. J. (2004). Evolution: The remarkable history of a scientific theory. New York, NY: Modern Library.

Lesk, M. (2004). Online data and scientific progress: Content in cyberinfrastructure. Paper presented at Digital Curation Centre, Edinburgh, Scotland. Retrieved from http://archiv.twoday.net/stories/337419

Loftus, E. F., \& Davis, D. (2006). Recovered memories. Annual Review of Clinical Psychology, 2, 469-498. doi:10.1146/annurev.clinpsy.2.022305.095315

Magnavita, J. J. (2005). Personality-guided relational psychotherapy: $A$ unified approach. Washington, DC: American Psychological Association. doi:10.1037/10959-000

Magnavita, J. J. (2006). In search of the unifying principles of psychotherapy: Conceptual, empirical, and clinical convergence. American Psychologist, 61, 882-892. doi:10.1037/0003-066X.61.8.882

Magnavita, J. J. (2008). Toward unification of clinical science: The next wave in the evolution of psychotherapy? Journal of Psychotherapy Integration, 18, 264-291. doi:10.1037/a0013490

Professional Psychology: Research and Practice, Vol. 44, No. 1 (February 2013): pg. 11-19. DOI. This article is (C) American Psychological Association and permission has been granted for this version to appear in e-Publications@Marquette. American Psychological Association does not grant permission for this article to be further copied/distributed or hosted elsewhere without the express permission from American Psychological Association. 
NOT THE PUBLISHED VERSION; this is the author's final, peer-reviewed manuscript. The published version may be accessed by following the link in the citation at the bottom of the page.

Martin, P. R., Weinberg, B. A., \& Bealer, B. K. (2007). Healing addiction: An integrated pharmacopsychosocial approach to treatment. Hoboken, $\mathrm{NJ}$ : Wiley.

Melchert, T. P. (2011). Foundations of professional psychology: The end of theoretical orientations and the emergence of the biopsychosocial approach. London, UK: Elsevier.

Messer, S. B., \& Winokur, M. (1980). Some limits to the integration of psychoanalytic and behavior therapy. American Psychologist, 35, 818827. doi:10:1037/0003-066x.35.9.818

Mitchell, M. (2009). Complexity: A guided tour. New York, NY: Oxford University Press.

Norcross, J. C. (2005). A primer on psychotherapy integration. In J. C.Norcross \& M. R.Goldfried (Eds.), Handbook of psychotherapy integration (2nd ed., pp. 3-23). New York, NY: Oxford University Press.

Norcross, J. C., Koocher, G. P., \& Garofalo, A. (2006). Discredited psychological treatments and tests: A Delphi poll. Professional Psychology: Research and Practice, 37, 515-522. doi:10.1037/07357028.37.5.515

Partnership for Solutions. (2004). Chronic conditions: Making the case for ongoing care. Baltimore, MD: Johns Hopkins University Press.

Popper, K. R. (1963). Conjectures and refutations: The growth of scientific knowledge. London, UK: Routledge.

Porges, S. W. (2011). The Polyvagal theory: Neurophysiological foundations of emotions, attachment, communication, and self-regulation. New York, NY: Norton.

Porter, R. (1997). The greatest benefit to mankind: A medical history of humanity. New York, NY: Norton.

Prochaska, J. O., \& Norcross, J. C. (2010). Systems of psychotherapy: A transtheoretical analysis (7th ed.). Belmont, CA: Brooks/Cole.

Quammen, D. (2006). The reluctant Mr. Darwin. New York, NY: Atlas Books.

Professional Psychology: Research and Practice, Vol. 44, No. 1 (February 2013): pg. 11-19. DOI. This article is (C) American Psychological Association and permission has been granted for this version to appear in e-Publications@Marquette. American Psychological Association does not grant permission for this article to be further copied/distributed or hosted elsewhere without the express permission from American Psychological Association. 
NOT THE PUBLISHED VERSION; this is the author's final, peer-reviewed manuscript. The published version may be accessed by following the link in the citation at the bottom of the page.

Randall, L. (2011). Knocking on heaven's door. New York, NY: Harper Collins.

Rodgers, J. L. (2010). The epistemology of mathematical and statistical modeling: A quiet methodological revolution. American Psychologist, 65, 1-12. doi:10.1037/a0018326

Rychlak, J. R. (2005). Unification in theory and method: Possibilities and impossibilities. In R. J.Sternberg (Ed.), Unity in psychology: Possibility or pipedream? (pp. 145-158). Washington, DC: American Psychological Association. doi:10.1037/10847-009

Seagull, E. A. (2000). Beyond mothers and children: Finding the family in pediatric psychology. Journal of Pediatric Psychology, 25, 161-169. doi:10.1093/jpepsy/25.3.161

Seligman, M. E. P., Rashid, T., \& Parks, A. C. (2006). Positive psychotherapy. American Psychologist, 61, 774-788. doi:10.1037/0003066X.61.8.774

Shah, S., \& Reichman, W. E. (2006). Psychiatric intervention in long-term care. In L.Hyer \& R. C.Intrieri (Eds.) Geropsychological interventions in long-term care (pp. 85-107). New York, NY: Springer.

Sroufe, L. A., Egeland, B., Carlson, E. A., \& Collins, W. A. (2005). The development of the person: The Minnesota study of risk and adaptation from birth to adulthood. New York, NY: Guilford.

Staats, A. W. (2005). A road to, and philosophy of, unification. In R. J.Sternberg (Ed.), Unity in psychology: Possibility or pipedream? (pp. 159-178). Washington, DC: American Psychological Association. doi: $10.1037 / 10847-010$

Sternberg, R. J. (2005). Unifying the field of psychology. In R. J.Sternberg (Ed.), Unity in psychology: Possibility or pipedream? (pp. 3-14). Washington, DC: American Psychological Association. doi: $10.1037 / 10847-001$

Suls, J., \& Rothman, A. (2004). Evolution of the biopsychosocial model: Prospects and challenges for health psychology. Health Psychology, 23, 119-125. doi:10.1037/0278-6133.23.2.119

Professional Psychology: Research and Practice, Vol. 44, No. 1 (February 2013): pg. 11-19. DOI. This article is (C) American Psychological Association and permission has been granted for this version to appear in e-Publications@Marquette. American Psychological Association does not grant permission for this article to be further copied/distributed or hosted elsewhere without the express permission from American Psychological Association. 
NOT THE PUBLISHED VERSION; this is the author's final, peer-reviewed manuscript. The published version may be accessed by following the link in the citation at the bottom of the page.

Truscott, D. (2010). Becoming an effective psychotherapist: Adopting a theory of psychotherapy that's right for you. Washington, DC: American Psychological Association. doi:10.1037/12064-000

U.S. Preventive Services Task Force. (2012). U.S. Preventive Services Task Force. Retrieved from http://www.uspreventiveservicestaskforce.org/

Wallin, D. J. (2007). Attachment in psychotherapy. New York, NY: Guilford.

Williams, W. H., \& Evans, J. J. (2003). Biopsychosocial approaches in neurorehabilitation: Assessment and management of neuropsychiatric, mood and behavioural disorders. Hove, UK: Psychology Press.

Wilson, E. O. (1998). Consilience: The unity of knowledge. New York, NY: Knopf.

Wood, A., \& Joseph, S. (2007). Grand theories of personality cannot be integrated. American Psychologist, 62, 57-58. doi:10:1037/003$066 \times 62.1 .57$

Wood, C. C., Berger, T. W., Bialek, W., Boahen, K., Brown, E. N., Holmes, T. C., ...Sweedler, J. V. (2006). Steering Group Report: Brain science as a mutual opportunity for the physical and mathematical sciences, computer science, and engineering. Arlington, VA: National Science Foundation.

\section{About the Author:}

Timothy P. Melchert received his Ph.D. in counseling psychology from the University of Wisconsin-Madison. He is an associate professor and the assistant vice provost for graduate programs at Marquette University. His research interests include the theoretical and scientific foundations for behavioral health care practice and family of origin influences on development and functioning.

Correspondence concerning this article should be addressed to Timothy P. Melchert, Department of Counselor Education and Counseling Psychology, 168F Schroeder Complex, Marquette University, Milwaukee, WI 53201. Email: tim.melchert@marquette.edu.

Professional Psychology: Research and Practice, Vol. 44, No. 1 (February 2013): pg. 11-19. DOI. This article is (C) American Psychological Association and permission has been granted for this version to appear in e-Publications@Marquette. American Psychological Association does not grant permission for this article to be further copied/distributed or hosted elsewhere without the express permission from American Psychological Association. 
NOT THE PUBLISHED VERSION; this is the author's final, peer-reviewed manuscript. The published version may be accessed by following the link in the citation at the bottom of the page.

Professional Psychology: Research and Practice, Vol. 44, No. 1 (February 2013): pg. 11-19. DOI. This article is (C) American Psychological Association and permission has been granted for this version to appear in e-Publications@Marquette. American Psychological Association does not grant permission for this article to be further copied/distributed or hosted elsewhere without the express permission from American Psychological Association. 